\title{
看護専門学校と看護大学の学生に括ける舆煙行動の此較
}

\author{
大井田隆*1, 尾 崎 米 厚*2, 岡 田 加奈子*3, 望 月 友美子*1, \\ 小椋正之*2, 箪輪畺 澄*2, 川口 毅*4 \\ *1 国立公采衛生院衛生行政学部, *2 国立公衆衛生院疫学部, $* 3$ 千葉大学教育学部, $* 4$ 昭和大学医学部公衆衛生学教室
}

\section{A Comparison of Smoking Habits between Nursing School and Nursing College Students}

\author{
Takashi OHIDA*1, Yoneatsu OSAKI*2, Kanako OKADA*3, Yumiko MOCHIZUKI*1, \\ Masayuki OGURA*2, Masumi MINOWA*2 and Takeshi KAWAGUCHI ${ }^{* 4}$ \\ ${ }^{*}$ Department of Public Health Administration, National Institute of Public health, Tokyo \\ *2 Department of Epidemiology, National Institute of Public Health, Tokyo \\ *3 Faculty of Education, Chiba University, Chiba \\ ${ }^{*}$ Department of Public Health, Showa University, School of Medicine, Tokyo
}

\begin{abstract}
This study was conducted through anonymous questionnaires in order to compare the smoking habits of nursing school students with those of nursing college students, and to identify factors that might possibly indicate causes of smoking habits, among students of two major courses (a 3-year nursing school course and a 4-year nursing college course) for becoming nurses. The subjects were students in two nursing schools and two nursing colleges in the Tokyo Metropolitan area.

The results showed that the smoking prevalence among nursing school students in the first to the third grades was $26 \%$, and that among nursing college students of the same grades was $12 \%$. As to factors related to smoking habits of the students the smoking patterns of mothers and friends were shown to largely influence those of the nursing students. Among nursing college students, $21 \%$ agreed to a smoking ban in their schools, compared with $14 \%$ of the nursing school students.
\end{abstract}

Keywords: nursing students (看護学生), smoking (喫煙), smoking prevalence（喫煙率）, smoking habits (喫煙行動),

\section{1. はじめに}

看護婦の喫煙率が一般成人女子に比べ ${ }^{1-6)}$ ，また， 将来看護婦になる看護学生の喫煙率も, 同じ年代の 大学生・短期大学生に比べ7-12) 高いことが報告されて いる。

一方, 我が国の女子高生の低い喫煙率と女子大生 及び20歳代一般女子の喫煙開始時期から推測して ${ }^{12,131}$, 看護学生も高校卒業後に喫煙開始するものと予想さ れる。従って, 看護婦養成施設 (看護専門学校, 看 護大学等) 在学中に, 喫煙行動が変化している可能 性があり，この時期の喫煙行動を分析することは，

受付 1999年 3 月 15 日 受理 1999年 7 月21日 Reprint requests to: Takashi OHIDA,

Department of Public Health Administration, National Institute of Public Health

4-6-1 Shirokanedai, Minato-ku, Tokyo 108-8638, Japan

TEL: +81(3)3441-7111 FAX: +81(3)3446-7194
看護婦の喫煙防止対策を推進する上でも必要である。 また，最近の看護婦喫煙行動に関する調査4-6)によ れば，20歳代准看護婦の喫煙率が極めて高く, 准看 護婦養成所での喫煙防止対策の実施が強調されてい た。しかしながら，これまで看護学生に関して養成 施設間での喫煙行動の比較研究がなされたことがな く，看護学生の喫煙行動を分析する上でも，どのよ うな看護学生が喫煙するかを明らかにすることは必 要である。

そこで, 本研究では, 最近増加した看護大学と看 護専門学校 (3 年過程) の看護学生の喫煙行動を比 較分析することによって，喫煙行動関連要因を検討 することを目的とした。

\section{2. 対象及び方法}

(1) 対象校及び対象者 
首都圏の 2 都道府県から，看護大学と看護専門学 校を 1 校づつ選んで（計 4 校），調査対象校とした。 調査時期は看護大学は1998年7月，看護専門学校は 1997年 7 月で，また調査対象者は 4 校の全看護学生 であったが，看護大学 1 校では 4 年生が実習のため 調査できなかったため, $1-3$ 年生を対象にした。

\section{（2）調查方法}

各施設の担当者（教官）を通じて，調査票の配布 及び回収を行った。回収方法は(1)対象者ひとりひと りに調查票と大小 2 つの封筒を渡し，(2)記入した調 査票を小さい封筒に入れ，(3)それを大きな封筒に入 れて，(4)大きな封筒に氏名を書いた後，担当者が回 収した。担当者は調査票を入れた小さい封筒だけを 我々に送付した。この方法を採用した理由は，無記 名性を確保し，誰も特定の看護婦及び看護学生の喫 煙状況を把握できないようにするためである。

\section{（３）調査票}

4 校とも自記式無記名の同じ調査票が用いられた。 調査票の項目については，具体的には1）現在まで の喫煙状況，2）周囲の者の契煙状況，3）二コチ ン依存度の程度 ${ }^{14)}, 4$ ) 自分の学校や病院を禁煙にす る必要があるかどうかの考え方，5）受動喫煙への 関心，6）性, 年齿令, 所属, 看護資格, 家庭状況, 及び 7 ) 自分の職業に対する考え等である。なお, 看護大学の 1 つが総合大学の看護学部であったため, 看護大学の質問票では友人の契煙状況についての質 問項目を，男性の友人と女性の友人の項目に分けた。

\section{（4）回収及び解析}

看護専門学校の調査では，2校に在学している421 名の学生を対象にし，404件の回収があったが（回収 率96\%)，14件が男性，2 件が白紙または不完全回答 で，17件が23歳以上であったため，解析からは除か れた（371件を解析）。23歳以上を解析から排除した 理由は今回の研究目的は 2 種類の看護婦養成施設の 環境因子と喫煙行動の関連性の検討であり，看護婦 養成施設に入学する以前に他の職場で働いていたあ るいは他の大学等に在学した可能性のある者を極力 排除するためである。

看護大学では, 在学している561名の学生（1校の 4 年生及び大学院生は除く）を476件の回収があり (回収率 $85 \%$ )，8 件が男性，2 件が不完全回答， 23 歳以上は73件で393件を解析の対象とした。

\section{(5) 統計処理}

統計処理は, SPSS for windowsを用い，検定は $\chi^{2}$ 検 定及び $\mathrm{t}$ 検定で行い，有意水準を $5 \%$ とした。

\section{3. 結 果}

看護専門学校の方が看護大学に比べて, 1 - 3 学年の 全学生の契煙率は統計学的に有意に高く $(\mathrm{p}<0.01)$, 特に 1 年生ではその差が顕著であった（表 1 ）。20歳 未満の契煙率では，看護専門学校 $22.7 \% \quad(\mathrm{n}=194)$ ，看 護大学生7.8\%（n=153）で有意に看護専門学校の学生 の方が高かった $\left(\chi^{2}\right.$ 検定 $\left.: \mathrm{p}<0.01\right)$ 。また，看護専門 学校の喫煙学生 95 人のうち, 55 人が 6 ヶ月以上契煙 し, 喫煙開始年齢は55人中 18 歳以上が 35 人 $(64 \%)$, 17 歳以下は 20 人 $(36 \%)$ であった。一方, 看護大学 では喫煙学生 52 人のうち, 23 人が 6 ヶ月以上喫煙し, 喫煙開始年齢は 23 人中 18 歳以上の者が 18 人 $(78 \%)$, 17 歳以下が 4 人 $(17 \%)$ で, 残り1（4\%）人が不 明であった。

Table 1 Smoking prevalence of nursing students examined by educational facilities (female students only)

\begin{tabular}{cccccc}
\hline & $\begin{array}{c}\text { Nursing school (2schools) } \\
\text { Smoking prevalence (n) }\end{array}$ & $\begin{array}{c}\text { Nursing college (2schools) } \\
\text { Smoking prevalence (n) }\end{array}$ & Significance \\
\cline { 2 - 2 } \cline { 5 - 6 } Nursing students & & & & \\
First grade & $20 \%(128)$ & & $3 \%(106)$ & $*$ \\
Second grade & $26 \%(126)$ & & $18 \%(126)$ & ns \\
Third grade & $32 \%(117)$ & & $14 \%(118)$ & $* *$ \\
Subtotal (first- & $26 \%(371)$ & & $12 \%(350)$ & $* *$ \\
$\quad$ third grade) & & & & $*$ \\
Fourth grade & & & $23 \%(43)$ & \\
Total & $26 \%(371)$ & & $13 \%(393)$ & $* *$ \\
\hline
\end{tabular}

Fourth grade nursing students were examined in only one college.

Smoking: Daily smoking + Occasional smoking

Significance: $\chi^{2}$ test $(2 \times 2)$

ns; not significant, ${ }^{* *} \mathrm{p}<0.01$

毎日喫煙者におけるFagerstromの 8 つ質問項目 ${ }^{14}$ からなるニコチン依存度の判定では看護大学で 3.91 $(n=23 / 23)$, 看護専門学校 $4.02(n=51 / 54)$ になり, 有 意の差（ $\mathrm{t}$ 検定）は認められなかった。

看護学生の喫煙に寄与する関連因子（周囲の喫煙 状況）を表 2 に示した。具体的には，「友人が喫煙し ている(いた）」と回答した看護専門学校学生の契煙 率は「いない」に比べ7.3倍も高く，表 2 からは周囲 の喫煙率について，看護専門学校と看護大学と比べ て関連因子の比の差はほとんど認められなかった。 また，周囲の喫煙状況では看護専門学校と看護大学 を比べると父親の喫煙率はほぼ同じであったが，母 親や兄弟姉妹では看護専門学校の方が喫煙率は統計 学的に有意に高かった。

生活上の悩みや満足度と喫煙行動の関係において (表 4)，看護大学で，友人との関係で悩みや苦労が 「大いにある」学生は喫煙者の $8 \%$ ，非喫煙者の $10 \%$ に，「全くない」学生は喫煙者の $15 \%$, 非契煙者の $2 \%$ になっており，その有意差が統計学的に認めら れた（p<0.01）。また，両方の学生とも看護学生にな ってよかったと答えた学生の比率は喫煙者群より非 契煙者群で有意に高くなっていた（p<0.01）。

学校や病院を全面禁煙にする考え方では（表5）, 
日衛誌（Jpn. J. Hyg.）第54巻 第 3 号 1999年10月

Table2 Factors contributing to smoking habits of smokers (female students only)

\begin{tabular}{|c|c|c|c|c|c|c|c|c|c|}
\hline \multirow[b]{3}{*}{ Father's smoking } & \multicolumn{4}{|c|}{ Nursing school } & \multicolumn{4}{|c|}{ Nursing college } & \\
\hline & Yes & No & Ratio & $95 \%$ C.I. & Yes & No & Ratio & 95\% C.I. & \\
\hline & $28.0 \%$ & $16.3 \%$ & 1.7 & $1.0-2.9$ & $15.2 \%$ & $8.9 \%$ & 1.7 & $0.9-3.3$ & \\
\hline Mother's smoking & $38.0 \%$ & $22.1 \%$ & 1.7 & $1.2-2.5$ & 21.6 & $11.3 \%$ & 1.9 & $1.1-3.5$ & \\
\hline Siblings' smoking & $37.5 \%$ & $16.9 \%$ & 2.2 & $1.5-3.2$ & $20.5 \%$ & $8.3 \%$ & 2.5 & $1.4-4.3$ & \\
\hline \multirow[t]{2}{*}{ Friends' smoking } & $36.3 \%$ & $5.0 \%$ & 7.3 & $3.2-16.1$ & $25.5 \%$ & $3.3 \%$ & 7.7 & $3.6-17.0$ & (female friends) \\
\hline & & & & & $18.2 \%$ & $5.1 \%$ & 3.6 & $1.6-8.2$ & (male friends) \\
\hline
\end{tabular}

Yes: Smoking prevalence among students with related factors (smoking of family members and friends).

No: Smoking prevalence among students without related factors.

Ratio: (A) / (B)

Smoking status includes current and former smoking.

95\% C.I. : 95\% confidence interval

Table 3 Smoking prevalence of family members and friends (female students only)

\begin{tabular}{lclc}
\hline & $\begin{array}{c}\text { Nursing schools } \\
(\mathrm{n}=371)\end{array}$ & $\begin{array}{c}\text { Nursing colleges } \\
(\mathrm{n}=393)\end{array}$ & Significance \\
Father & $71 \%$ & $68 \%$ & $\mathrm{~ns}$ \\
Mother & $22 \%$ & $13 \%$ & $* *$ \\
Siblings & $37 \%$ & $28 \%$ & $*$ \\
Friends & $64 \%$ & $42 \%$ (female) & \\
& & $60 \%$ (male) & \\
\hline
\end{tabular}

Smoking prevalence includes current and former smoking.

Significance: $\chi^{2}$ test $(2 \times 2)$

ns; not significant, ${ }^{*} \mathrm{p}<0.05,{ }^{* *} \mathrm{p}<0.01$

看護大学の学生の方が看護専門学校に比べ全面禁煙 に賛成する者の率が有意に高かく（ $\mathrm{p}<0.01 ）$ ，また受 動契煙に対する関心についても看護大学生の方が関 心を持っている率が有意に高かった（p<0.01）。

\section{4. 考 察}

\section{(1) 喫煙率}

今回の調査で同じ看護婦を目指す看護学生におい て看護大学と看護専門学校という学歴の差による喫 煙率の違いが観察された。女性の学歴と喫煙率の関 係は斉藤 ${ }^{15)}$ が妊婦を対象にした調査で, 専門学校卒 の喫煙率 $5.3 \%$, 大学卒 $2.0 \%$ と報告し, その関係が認 められていた。また, Osakiら ${ }^{16)}$ は女子高校生の喫煙 率と学校関連要因の中で, 最も相関関係があったの
は大学進学率であると報告し, 学歴と喫煙率との関 係を示唆している。今回の調査でも6ヶ月以上毎日喫 煙している学生の契煙開始において, 看護専門学校 の方が17歳以下の割合が高いこと及び未成年学生の 喫煙率に差があることはOsakiらの報告を支持するも のと考えている。さらに，看護婦の喫煙率において， 大井田ら ${ }^{4,6)}$ や小林 $^{5)}$ (20歳代の看護婦と准看護婦の 喫煙率の違いから, 看護専門学校と准看護婦養成施 設での看護学生の喫煙率の差を推測していた。

今回の調査は首都圈だけで実施されため, 我が国 を代表するものではないが, 今回の結果と前述した 報告から看護学生の喫煙率は, 看護大学, 看護専門 学校, 准看護婦学校の順で低くなるものと考えられ る。しかし, 看護大学生の喫煙率が低いと言っても, 他の女子大生に比べて低いとは言えない。最近 (1990，95年）の調査で, 塩田ら ${ }^{17)}$ は千葉県と山口県 の大学に在学している未成年女子大生の喫煙率は 0 $3 \%$ と報告しており, 今回の看護大学における未成 年女子大生に比べても低い值であった。

このような状況を見ても，喫煙している学生は将 来看護婦になるということから禁煙を考えるべきで ある。Reeveら ${ }^{18)}$ は, 契煙看護婦と非喫煙看護婦では 患者に対する健康教育の取り組む姿勢が違うことを 報告しており，我が国の看護婦もそろそろ契煙防止 対策を日本看護協会が中心になって実施する時期に 来ているものと考える。また, 今回の調査で看護専

Table 4 Smoking status compared with career satisfaction and relationship with friends (female students only)

\begin{tabular}{|c|c|c|c|c|c|c|c|}
\hline \multicolumn{8}{|c|}{ Do you have any trouble or suffering in your relationship with your friends? } \\
\hline & & Severely & Moderately & Little & Never & Total & Significance \\
\hline \multirow[t]{2}{*}{ Nursing school } & Smoker $(n=94)$ & $6 \%$ & $53 \%$ & $32 \%$ & $10 \%$ & $100 \%$ & ns \\
\hline & No-smoker $(\mathrm{n}=276)$ & $5 \%$ & $45 \%$ & $42 \%$ & $8 \%$ & $100 \%$ & \\
\hline \multirow[t]{2}{*}{ Nursing college } & Smoker $(n=52)$ & $8 \%$ & $48 \%$ & $29 \%$ & $15 \%$ & $100 \%$ & ** \\
\hline & No-smoker $(n=341)$ & $10 \%$ & $56 \%$ & $33 \%$ & $2 \%$ & $100 \%$ & \\
\hline
\end{tabular}

Are you satisfied to be a nursing student?

\begin{tabular}{|c|c|c|c|c|c|c|}
\hline & & Yes & No & Not specified & Total & Significance \\
\hline \multirow[t]{2}{*}{ Nursing school } & Smoker $(n=95)$ & $51 \%$ & $13 \%$ & $37 \%$ & $100 \%$ & $* *$ \\
\hline & No-smoker $(n=276)$ & $60 \%$ & $4 \%$ & $36 \%$ & $100 \%$ & \\
\hline \multirow[t]{2}{*}{ Nursing college } & Smoker $(n=52)$ & $52 \%$ & $12 \%$ & $37 \%$ & $100 \%$ & $* *$ \\
\hline & No-smoker $(n=341)$ & $68 \%$ & $3 \%$ & $29 \%$ & $100 \%$ & \\
\hline
\end{tabular}

Significance: $\chi^{2}$ test $(2 \times 4,2 \times 3)$

ns: not significant, ${ }^{* *}: \mathrm{p}<0.01$ 
日衛誌（Jpn. J. Hyg.）第54巻 第 3 号 1999年10月

Table 5 Opinions about smoking (female students only)

\begin{tabular}{|c|c|c|c|c|c|}
\hline & $\begin{array}{l}\text { Complete } \\
\text { ban }\end{array}$ & $\begin{array}{c}\text { Partial } \\
\text { ban }\end{array}$ & $\begin{array}{c}\text { No } \\
\text { restrictions }\end{array}$ & Total & Significance \\
\hline \multicolumn{6}{|l|}{ Smoking ban in their own schools } \\
\hline Nursing School $(n=370)$ & $14 \%$ & $82 \%$ & $4 \%$ & $100 \%$ & $* *$ \\
\hline Nursing College $(n=388)$ & $21 \%$ & $78 \%$ & $1 \%$ & $100 \%$ & \\
\hline \multicolumn{6}{|l|}{ Smoking ban in hospitals } \\
\hline Nursing School $(n=368)$ & $22 \%$ & $76 \%$ & $2 \%$ & $100 \%$ & ** \\
\hline Nursing College $(n=393)$ & $48 \%$ & $51 \%$ & $0 \%$ & $100 \%$ & \\
\hline & Interested & Not & Not specified & Total & \\
\hline \multicolumn{6}{|l|}{ Interest in harm from passive smoking } \\
\hline Nursing School $(n=359)$ & $62 \%$ & $7 \%$ & $31 \%$ & $100 \%$ & ** \\
\hline Nursing College $(n=390)$ & $89 \%$ & $3 \%$ & $9 \%$ & $100 \%$ & \\
\hline
\end{tabular}

Significance: $\chi^{2}$ test $(2 \times 3)$

${ }^{* *}: \mathrm{p}<0.01$

門学校の喫煙率は高かったが, 毎日喫煙者のニコチ ン依存度は双方とも概ね同じような值であった。し かし, 看護学生のニコチン依存度をこれ以上上げな いためにも，一刻も早く禁煙教育の実施にあたるべ きであり，看護婦養成施設での契煙防止教育は必須 科目にすべきなのかもしれない。Charltonら 19) は喫煙 防止教育の実施により, 英国の看護婦養成施設で学 生の年歯令が上がるごとに猰煙率が低下することを報 告しており，我が国の看護学生とはまったく反対の 傾向を示している。

さらに表 5 から, 看護大学の方が学校や病院の全 面禁煙に賛成をする学生が多かったことは, 看護大 学の方が喫煙防止教育を実施している可能性もある が, しかし, 表 1 から看護大学生の喫煙率は 1 年か ら 4 年にかけ $3 \%$ から $23 \%$ に昇しており, 上り効 果的な喫煙防止教育が求められる。また, 看護専門 学校では 1 年生で既に喫煙率が $20 \%$ にもなており， 早急に禁煙教育が必要と思われる。

今回の調査は首都圏のわずか 4 校の調査であり, 全国にある看護婦養成施設がどのような喫煙防止教 育を実施しているかの調査は今後の研究課題である。

\section{（2）喫煙関連因子}

表 2 から周囲の「喫煙なし」に対する「喫煙あり」 の学生の喫煙率比は看護大学, 看護専門学校ともほ ぼ同じであるとことから, 周囲の喫煙の影響は変わ らないものと考えられる。しかし, 表 3 からは周囲 の契煙率，特に母親の契煙率に大きな差があり，こ れが看護大学と看護専門学校における喫煙率の差に 対する原因のひとつと推測される。松村 ${ }^{20)}$ は女子大 生の契煙行動は母親の契煙に強く影響されると報告 しており，今回の調査も同じような結果であった。 また，いくつかの女子大生や看護学生の調査 ${ }^{8-10,20)}$ で は，友人の契煙行動が本人の契煙行動に影響すると 報告している。今回の調査では友人について看護大 学では女子と男子の友人に分けたため, 単純に比較
はできなかったが, 表 3 のからは看護専門学校学生 の友人の方が看護大学に比べ喫煙率が高いと考えら れ, この友人の喫煙率の差も母親同様, 看護専門学 校生と看護大学生の喫煙率の違いに対する原因のひ とつと推測される。

看護婦，看護学生とストレスとの関係については 数多く報告されている ${ }^{21-25)}$ 。しかし, 今回の看護大学 においては「友人との関係で悩みや苦労がある」と 回答した学生に喫煙傾向がなく, 今までの調査結果 とは異なった結果になってしまった。看護専門学校 の学生ではそのような傾向はなく, 看護大学生では このようなストレスが喫煙行動にまでは至らなかっ た可能性もあるが，今回の調査ではストレスに関す る調査項目はほとんどなく，同じょうなストレスが 喫煙行動と関係する集団としない集団があるかどう か今後さらに検討する必要がある。

本研究の実施にあたり，御指導いただきました橋 本修二助教授（東京大学医学部健康科学）に対し束 心より感謝申し上げます。

\section{文 献}

1)大島 明, 中村正和. 大阪府下某職域における喫 煙の実態. 日公衛誌 $1988 ; 35: 527-30$.

2) Sacker A. Smoking habits of nurses and midwives. J Adv Nurs 1990 ; 15 : 1341-6.

3) Adriaanse H, Reek J, Zandbert L, et al. Nurses' smoking world wide. A review of 73 surveys on nurses' tobacco consumption in 21 countries in period 1959-1988. Int J Nurs Stud 1991; 28 : 36175.

4) 大井田隆, 尾崎米厚, 望月友美子, 他. 看護婦の 喫煙行動に関する調査研究。日公衛誌 $1997 ; 44$ ： 694-701.

5) 小林友美子. 看護婦の喫煙問題. ヘルスサービス 
・たばこのない世界を開く空。東京：保健同人社, $1993 ; 83-100$.

6) 大井田隆, 尾崎米厚, 望月友美子, 他. 三重県に おける看護婦の喫煙行動に関する調査研究. 日衛 誌 $1999 ; 53: 611-7$.

7) 水谷美穂子. 看護学生の喫煙実態調査. 看護学雑 誌 $1983 ; 7: 916-22$.

8) 園田恭一, 会田敬志, 日高宗子. 女性喫煙の保健 社会学的研究一看護学生を対象として一。日公衛 誌 $1984 ； 31$ (附録）：450.

9) 古田真司, 西村知子. 未成年女子の飲酒と喫煙行 動に要因の検討一飲酒および喫煙行動とその意識 の相違について一. 学校保健研究 $1989 ; 31: 235$ 43.

10) 岡田加奈子. 女子短期大学生の喫煙行動の実態及 び関連因子の検討。帝京平成短期大学紀要 1992 ; $2: 37-40$.

11) Okada K. Smoking behavior among student nurses in Japan. The Japan Academy of Nursing Science, Kobe: Second International Nursing Research Conference in Kobe, $1995: 300$.

12) 岡田加奈子. 一般学生と看護学生の喫煙行動と禁 煙教育. 帝京平成短期大学紀要 $1993 ; 3: 55-62$.

13) 尾崎米厚, 木村博和, 算輪䢐澄。わが国の中・高 生の喫煙実態に関する全国調查（第 2 報）生徒の 喫煙に関連する要因。日公衛誌 $1993 ; 40 ： 959-68$.

14) 中村正和, 大島 明. 禁煙のための行動科学的ア プローチ. 日本プライマリ・ケア学会雑誌 1991 ; $14: 29-37$.

15）斉藤麗子. 妊婦と夫の喫煙状況と出生児への影響. 日公衛誌 $1991 ； 38 ： 124-31$.

16) Osaki $Y$, Minowa M. School factor and smoking prevalence among high school students in Japan. Environmental Health and Preventive Medicine $1996 ; 1: 107-13$.

17) 塩田正俊, 松原 茂, 亀井美和子, 岩本圭史. 未 成子大学生の喫煙行動・意識および知識の地域 差, 学部差, 学年差および調查年代差. 日公衛誌 $1997 ; 44$ : 247-55.

18) Reeve K, Adams J, Kouzekanani K. The nurses as exemplar: smoking status as a predictor of attitude toward smoking and smoking cessation. Cancer Pract $1996 ; 4: 31-3$.

19) Charlton A, While D, Mochizuki Y. A survey into the smoking habits of nursing students. Nursing Times $1997 ; 93$ (September24) : 57-60.

20）村松園江. 女子学生の喫煙行動と生活習慣の係わ りに関する研究。日公衛誌 $1985 ； 32 ： 675-86$.

21) Tagliacozzo R, Vaughn S. Stress and smoking in hospital nurses. Am J Public Health 1982 ; 72 : 4418

22) Murray M, Swan AV, Mattar N. The task of nursing and risk of smoking. J Adv Nurs $1983 ; 20$ : 553-7.

23) Wagner TJ. Smoking behavior of nurses in western New York. Nurs Res $1985 ; 34: 58-60$.

24) DeMello DJ. Smoking and attitudes toward smoking among clinical nurse specialists, critical care nurses, medical surgical nurses. Oncol Nurs Forum $1989 ; 16: 795-9$.

25) Becker DM, Myers AH, Sacci M, et al. Smoking behavior and attitudes toward smoking among hospital nurses. Am J Public Health 1986 ; 76 : 1449-51. 